\title{
ANÁLISE DOS SERVIÇOS ECOSSISTÊMICOS DE UM ESPAÇO VERDE NO MUNICÍPIO DE VOLTA REDONDA - RJ
}

\author{
ANALYSIS OF THE ECOSYSTEM SERVICES OF A GREEN SPACE \\ IN VOLTA REDONDA CITY - RJ
}

\author{
Bruno Rocha Silva Setta \\ *Biólogo, mestrando em Engenharia Urbana e Ambiental pela Pontifícia Universidade \\ Católica do Rio de Janeiro, Rio de Janeiro - RJ. \\ E-mail: brunosetta@hotmail.com
}

\begin{abstract}
RESUMO
A degradação dos ecossistemas naturais, impulsionada pela urbanização desenfreada e pela falta de planejamento em séculos passados, provocou sérios impactos ambientais à saúde pública e ao meio ambiente. Os serviços ecossistêmicos, que são os benefícios diretos e indiretos obtidos pelo homem a partir do funcionamento dos ecossistemas, foram afetados e tornaram as cidades, de maneira geral, ecossistemas de baixa resiliência e, consequentemente, de baixa qualidade de vida. Hoje, há uma crescente preocupação com as interconexões entre o estado dos ecossistemas naturais e o bem-estar das populações humanas, onde os planejadores e autoridades buscam por alternativas que não ou pouco interferem nos fluxos naturais. Com base nisto, este trabalho analisa e descreve as inter-relações entre os serviços ecossistêmicos e o bem-estar humano, e propõe diretrizes paisagísticas alternativas para os problemas ambientais encontrados em um espaço verde no município de Volta Redonda, localizado no sul do Estado do Rio de Janeiro.
\end{abstract}

Palavras-chave: Serviços ecossistêmicos; sustentabilidade; espaços verdes.

\section{ABSTRACT}

The degradation of natural ecosystems, propelled by unrestrained urbanization and lack of planning in past centuries, brought serious environmental impacts to public health and to the environment. The ecosystem services, which are the direct and indirect 
benefits gained by mankind from the functioning of ecosystems, have been affected and made the cities, in general, ecosystems of low resilience and, consequently, of low quality of life. Nowadays, there is a growing concern about the interconnections between the conditions of natural ecosystems and the welfare of human populations, where planners and authorities look for alternatives that do not, or scarcely, interfere with the natural flows. On this basis, this work analyzes and describes the interrelationships between ecosystem services and human welfare, proposing alternative landscaping guidelines for environmental problems found in a green space in the city of Volta Redonda, in the southern region of Rio de Janeiro State.

Keywords: Ecosystem Services; Sustainability; Green Spaces.

\section{INTRODUÇÃO}

Atualmente somos mais de sete bilhões de pessoas e mais da metade reside em áreas urbanas. Com isto, a demanda por espaço e recursos naturais, principalmente por água, alimentos e energia, cresce e gera diversos impactos ao meio ambiente. A degradação ambiental persiste e se intensifica cada vez mais, sendo as atividades industriais e o espraiamento urbano desordenado os principais agentes causadores.

A cidade é o hábitat humano por excelência e está constantemente em transformação. Um momento de grande transformação das cidades, sem dúvida, foi período da Revolução Industrial, ocorrida no final do século XVIII, que propiciou a vinda de milhares de pessoas do campo para as mesmas. No entanto, o desenvolvimento urbano não ocorreu de forma planejada e não houve preocupação com a preservação do meio ambiente, onde muitas cidades não apresentavam esgoto tratado, a poluição era generalizada (água, solo e ar), os surtos de doenças eram frequentes e as construções não favoreciam a circulação de ar.

A partir da Revolução Industrial, o processo de urbanização se intensificou em diversas cidades do mundo, caracterizado também pela falta de planejamento urbano e pelo desordenamento, sobretudo nos países em desenvolvimento. Nas últimas décadas, foi notório o empobrecimento das paisagens urbanas na maioria das cidades brasileiras, pois a preocupação dos planejadores e das autoridades municipais ainda está focada nas características socioeconômicas, desprezando a incorporação dos 
elementos naturais das paisagens. Com isto, houve um grande aumento de áreas sujeitas às inundações devido à ocupação de locais inapropriados, desmatamentos, impermeabilização dos solos, descartes inadequados de resíduos urbanos sobre encostas e nos cursos d'água, agravando ainda mais os problemas ambientais nas grandes cidades.

Todas essas práticas resultaram na redução da qualidade de vida nas cidades. Contudo, nos últimos anos, a percepção ambiental ganhou status e passou a ser incorporada nos projetos urbanísticos, através da criação de parques e jardins ou da restauração de áreas urbanas degradadas. Estes espaços verdes são áreas plantadas de vegetação (LLARDENT, 1982) que melhoram a qualidade de vida da população, pois suavizam o aspecto cinzento da cidade e contribuem para a manutenção e para o bom funcionamento dos serviços ecossistêmicos. Tais serviços são os benefícios direta e indiretamente apropriados pelo homem a partir do funcionamento de ecossistemas naturais (DAILY, 1997; COSTANZA et al., 1997; DE GROOT et al., 2002; MEA, 2005).

São considerados como exemplos de serviços ecossistêmicos: a regulação e amenização de eventos climáticos extremos, polinização de plantas, controle da erosão, áreas de contemplação e recreação e dentre outros. Eles são importantes para as atividades econômicas porque fornecem os recursos necessários à produção de bens e serviços econômicos e são essenciais para o bem-estar humano, já que suportam as condições de vida das espécies humana e não humanas (MEA, 2005). No entanto, o fato destes serviços não serem precificados como qualquer outro bem ou serviço do mercado, faz com que não haja incentivos para sua preservação, havendo uma superexploração ou até mesmo a perda total (ANDRADE, 2010), o que não deveria ocorrer.

Logo, as cidades tornaram-se ecossistemas vulneráveis aos efeitos severos das mudanças climáticas, pois perderam a sua resiliência. O grande desafio agora é diminuir a pegada ecológica e planejar cidades resilientes para que estas sejam sistemas sustentáveis a longo prazo. Diante disto, o presente trabalho pretende analisar as características ecossistêmicas e propor soluções alternativas para o beneficiamento harmônico (homem $x$ natureza), em um espaço verde localizado no município de Volta Redonda (RJ). 


\section{O MUNICÍPIO DE VOLTA REDONDA}

O município de Volta Redonda, criado pela Lei $n^{\circ} 2185$ de 17 de julho de 1954, localiza-se no trecho médio do vale do rio Paraíba do Sul, entre as Serras do Mar e da Mantiqueira, entre os paralelos $22^{\circ} 24^{\prime} 11^{\prime \prime}$ e $22^{\circ} 38^{\prime}$ de latitude sul e os meridianos

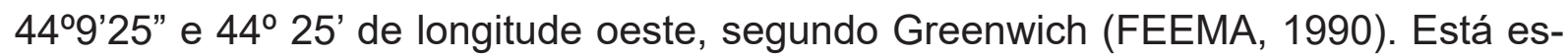
trategicamente localizado entre as duas principais capitais do Brasil, Rio de Janeiro e São Paulo, e a poucos minutos da Rodovia Presidente Dutra, uma das principais e mais movimentadas rodovias do país.

A figura abaixo ilustra a localização geográfica do município de Volta Redonda, demonstrando a sua proximidade com as cidades do Rio de Janeiro e São Paulo.

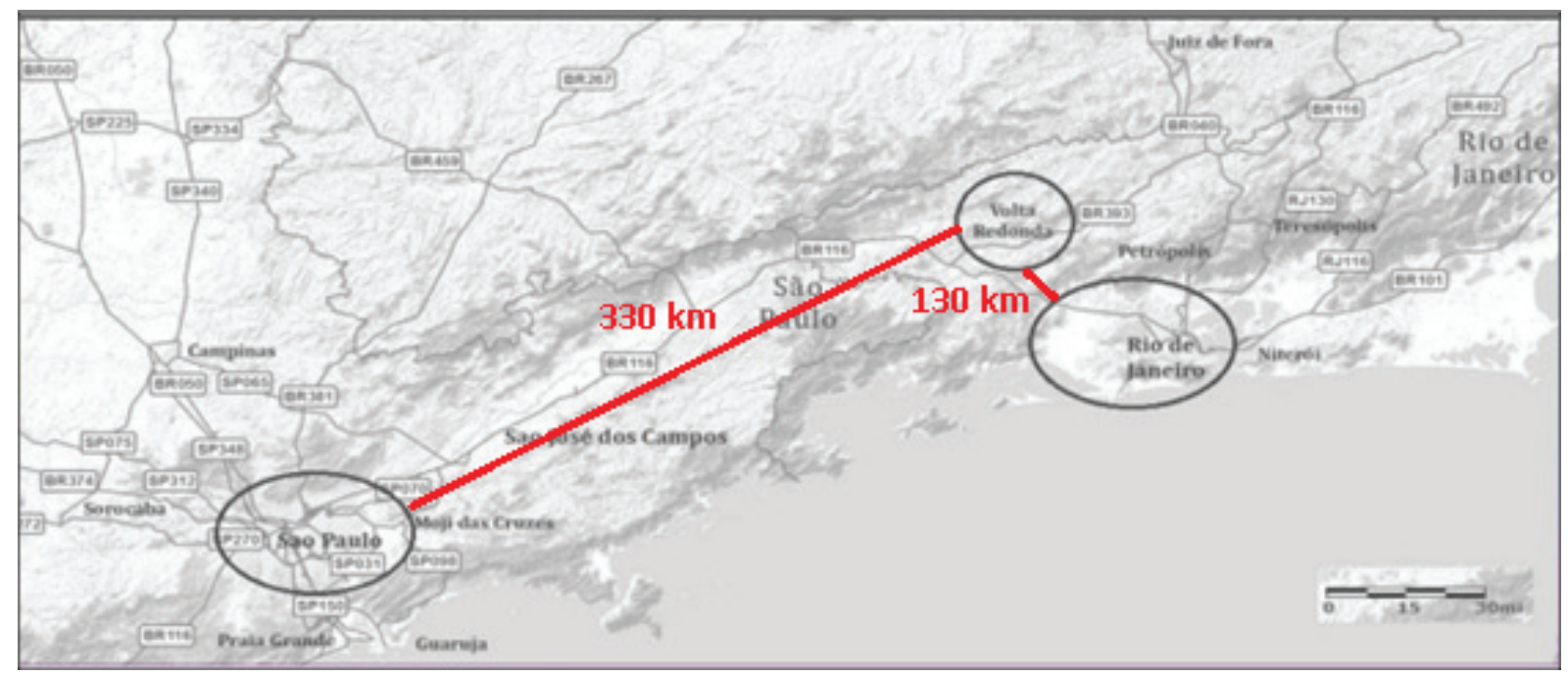

Figura 1 - Posição geográfica de Volta Redonda próxima às cidades do Rio de Janeiro e São Paulo. Fonte: Adaptado de Heckmaier, 2012.

Assim como os municípios vizinhos de Barra Mansa e Resende, o município de Volta Redonda é considerado uma das principais economias do sul do estado do Rio de Janeiro. Constitui-se em uma área de atração demográfica devido à industrialização, comércio e prestação de serviços. Além disto, é o município mais populoso do sul do estado com 262.970 mil habitantes (IBGE, 2015). 


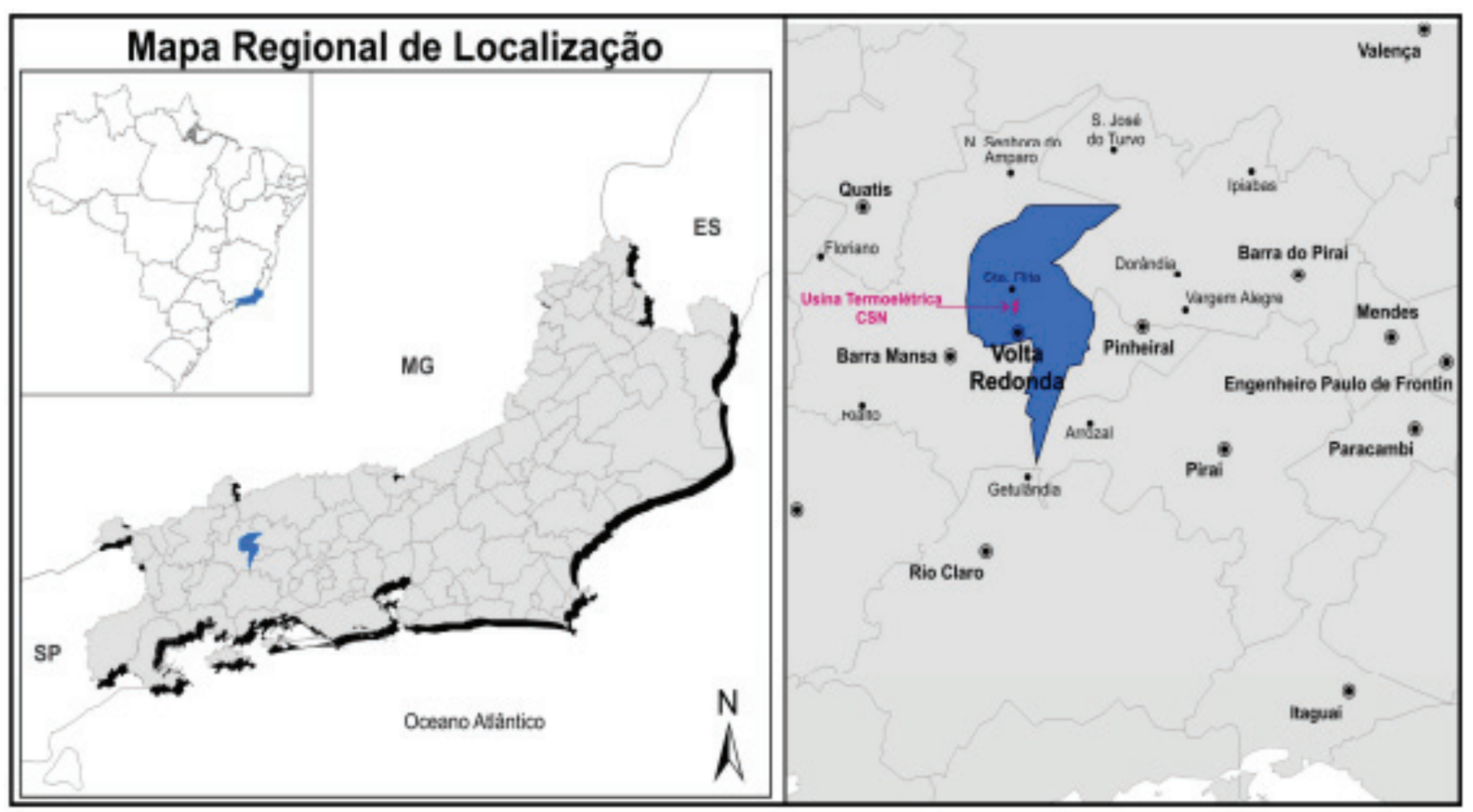

Figura 2 - Localização geográfica do Município de Volta Redonda na Região Sul Fluminense do Estado do Rio de Janeiro. Fonte: DIAS \& GARCIA, 2014.

De acordo com Fontes \& Lamarão (2006), existem claramente definidos três períodos que marcam a evolução político-industrial e urbana do município:

Num primeiro momento, que se estende de 1941 a 1954, a CSN centraliza e dirige o desenvolvimento de Volta Redonda, implantando e administrando a usina e o núcleo urbano, o qual, durante esses anos, não passava de um distrito do município de Barra Mansa. Em seguida, entre 1954 e 1967, com a emancipação políticoadministrativa do distrito e a conseqüente criação do município de Volta Redonda, proprietários de terras e comerciantes fazem valer mais livremente seus interesses; a expansão "natural" da cidade ganha novo ímpeto, ao mesmo tempo em que a CSN continua mantendo sob controle seu vasto patrimônio urbano. $E$, finalmente, a partir de 1967, a Companhia dá início à transferência de seu patrimônio e encargos urbanos à Prefeitura Municipal, redefinindo suas responsabilidades na evolução urbana de Volta Redonda. 

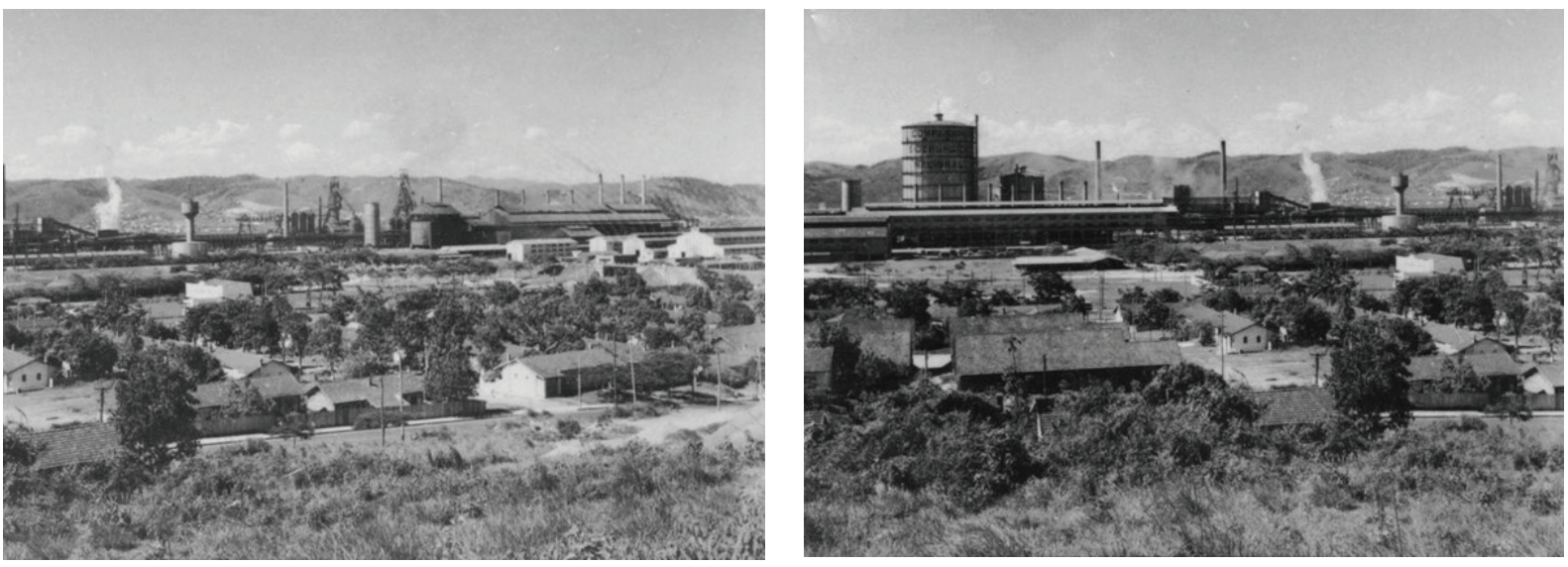

Figuras 3 e 4 - Imagens do início do crescimento urbano do Município de Volta Redonda, entre as décadas de 40 e 50, e a CSN ao fundo. Fonte: IBGE, 2015.

A expansão urbana acarretou danos significativos ao meio ambiente, sobretudo ao que se refere às consequências geradas pela industrialização, pois não houve qualquer planejamento que considerasse a preservação e a manutenção dos recursos naturais. Além da instalação da maior siderúrgica da América Latina, o que faz com que o setor industrial seja o mais representativo para a economia local, nos últimos anos tem se observado o crescimento do comércio e do setor de serviços (LIMONAD, 2001).

O fato do município estar em um fundo de vale (Vale do rio Paraíba - entre as serras do Mar e Mantiqueira) impede a livre circulação dos ventos, o que dificulta bastante a dispersão atmosférica (IPPUVR, 1994). É considerado o segundo município com o maior potencial poluidor do Estado do Rio de Janeiro, ficando apenas atrás da capital (SOR et al., 2008). Este quadro se deve às atividades industriais presentes, principalmente a metalurgia e a siderurgia, e ao intenso tráfego de veículos que tem ocasionado em diversas internações por doenças respiratórias, grande parte pela exposição dos indivíduos ao monóxido de carbono (PAIVA, 2014).

\section{ESPAÇO VERDE E O CÓRREGO CACHOEIRINHA}

O presente trabalho se desenvolve em um espaço verde localizado no bairro Vila Santa Cecília, um bairro de uso misto do Município de Volta Redonda, chamado de Jardim dos Inocentes. Através da utilização do software Google Earth, foi possível delimitar a área de 9.901,276 m². No entorno possui residências, algumas escolas e pequenos 
estabelecimentos comerciais e shoppings centers, além do centro cultural Memorial Zumbi dos Palmares e da Biblioteca Municipal de Volta Redonda.

O Jardim dos Inocentes está inserido numa área da cidade bastante movimentada, com intenso tráfego de veículos, circulação de pessoas e mal era usado para atividades de recreação e lazer. No entanto, este espaço recebeu investimentos ambientais em cerca de R\$300 mil com o Programa Municipal de Arborização Urbana e Revitalização Arbórea, em 2010, que previa o plantio de 175 novas mudas de árvores nativas da Mata Atlântica, como quaresmeira, pitangueira, ipê amarelo e araçá (PORTAL VR, 2015). Após o plantio, a área deixou de ser apenas de "passagem" e passou a ser mais frequentada pela população e moradores e a receber mais animais da fauna local, sobretudo de aves.

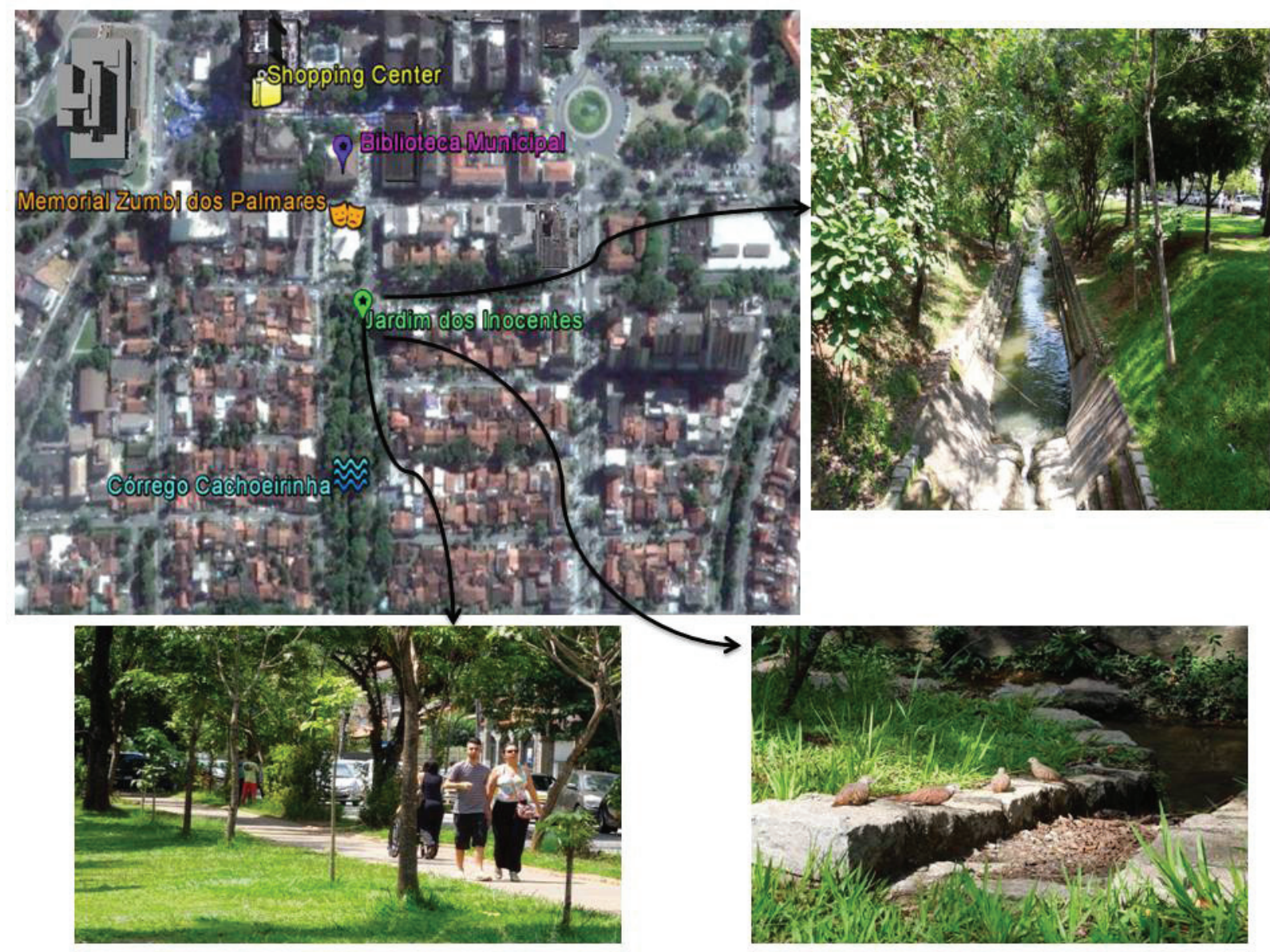

Figura 5 - Localização geográfica e imagens do Jardim dos Inocentes. Fonte: Google Earth, 2015; Fotos: Próprio autor. 
Dentro do Jardim dos Inocentes percorre o córrego Cachoeirinha, um afluente do rio Brandão que é um dos principais afluentes do rio Paraíba do Sul no município. Dentro do perímetro urbano do município, este córrego sofreu bastante com a poluição durante o crescimento do município e até hoje recebe grandes quantidades de esgoto doméstico despejados diariamente, principalmente na região central do bairro Vila Santa Cecília.

Nas últimas décadas, houve grandes problemas com enchentes que provocaram grandes transtornos e prejuízos consideráveis a moradores e comerciantes da região central do bairro Vila Santa Cecília, incluindo a área do Jardim dos Inocentes. De acordo com Rodrigues (2008), os principais fatores que contribuíram para estes eventos foram:

- a expansão de bairros e a construção de loteamentos e conjuntos residenciais que impermeabilizaram grandes áreas a montante, eliminando grandes áreas que atuavam com os reservatórios naturais no

- amortecimento das vazões;

- o assoreamento do curso inferior devido ao desmatamento e erosão das encostas, e a desestabilização e erosão das margens, intensificando o transporte sólido;

- o despejo de lixo urbano, esgoto doméstico e entulhos de construções diretamente nas calhas, contribuindo para acelerar o processo de assoreamento.

No relatório elaborado pelo Instituto de Pesquisa e Planejamento Urbano de Volta Redonda (IPPUVR, 1997), foram apontados alguns pontos de alagamento no Município de Volta Redonda, inclusive no córrego Cachoeirinha próximo ao Jardim dos Inocentes (P3). Alguns deles estão demonstrados na Figura 6 abaixo. 


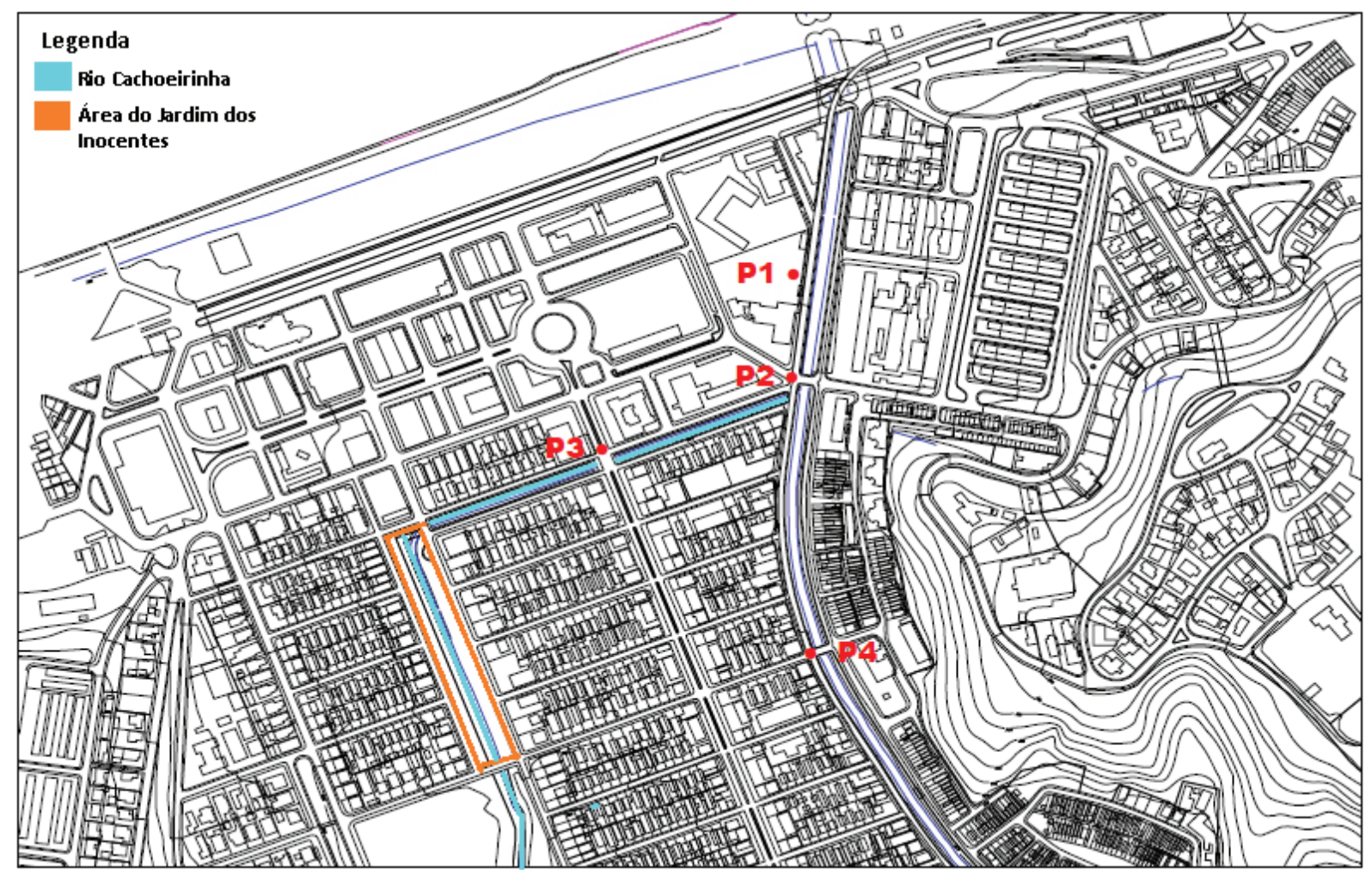

Figura 6 - Mapa da região de Volta Redonda indicando alguns pontos de alagamento. Fonte: Adaptado de IPPUVR, 1997.

\section{ANÁLISE DOS SERVIÇOS ECOSSISTÊMICOS}

Com a crescente preocupação sobre as interconexões entre o estado dos ecossistemas naturais e o bem-estar das populações humanas, planejadores e autoridades buscam por alternativas que não ou pouco interferem nos fluxos dos serviços ecossistêmicos. Dentre elas, a forma mais viável para qualquer projeto urbano seria a preservação de áreas verdes remanescentes, assim o funcionamento natural dos ecossistemas permaneceria, trazendo benefícios tanto para homem quanto para o ecossistema em si.

De acordo com a Avaliação Ecossistêmica do Milênio (2003), os serviços ecossistêmicos podem ser ordenados em quatro categorias primárias, tais como: i) serviços de regulação; ii) serviços de suporte; iii) serviços de provisão; e iv) serviços de culturais. A Tabela 1 a seguir demonstra as categorias e alguns exemplos de cada uma. 
Tabela 1 - Serviços ecossistêmicos segundo categorias.

\section{Serviços ecossistêmicos}

Tipos de serviços

Exemplos

Regulação climática; regulação de distúr-

Serviços de regulação bios; regulação e oferta de água; retenção do solo; regulação de nutrientes; tratamento de resíduos; polinização

Serviços de suporte

Formação do solo; produção de oxigênio; produção primária

Serviços de provisão

Alimentos; matéria orgânica; recursos genéticos; recursos ornamentais

Recreação e lazer; informação estética;

Serviços culturais informação artística e cultural; informação

histórica e espiritual

Fonte: MEA, 2003.

Todos os tipos de serviços ecossistêmicos foram identificados no Jardim dos Inocentes através das visitas locais realizadas. No entanto, os serviços de provisão, regulação e culturais foram mais expressivos na área, enquanto os de suporte foram menos expressivos.

Provavelmente desde quando ocorreu a revitalização da área, em 2010, com o Programa Municipal de Arborização Urbana e Revitalização Arbórea o qual propiciou a plantação de diversas espécies de árvores da flora, sobretudo as frutíferas, os serviços de provisão (alimentos) se perpetuaram ao longo dos anos. Por causa disto, foi observado um grande número de insetos e aves que têm como fonte de alimento as frutas ou outras partes constituintes delas. 
Dentre os serviços de regulação, pode-se destacar o serviço de regulação climática. Em um dia de visita foi verificado, com o auxílio de um termômetro, que a temperatura ambiente fora da área do Jardim dos Inocentes estava $27,8^{\circ} \mathrm{C}$, enquanto que no interior estava $27,3^{\circ} \mathrm{C}$. Ou seja, há uma amenização climática devido à presença da arborização e do córrego Cachoeirinha, os quais apresentam como fatores preponderantes para esta regulação os processos de evapotranspiração e da evaporação, respectivamente.

Os serviços culturais mais identificados foram os de recreação e lazer. Com a revitalização em 2010, a população e os moradores locais passaram a visitá-lo com mais freqüência. O sombreamento das árvores, áreas pavimentadas para a prática de atividades físicas, como caminhadas ou corridas, e áreas verdes livres para recreação ou contemplação são alguns elementos que motivam as pessoas a freqüentarem mais o Jardim dos Inocentes.

Apesar de identificadas algumas melhorias no Jardim dos Inocentes, os problemas ambientais que já existiam antes da revitalização ainda continuam. Dentre eles podemos citar: o lançamento de esgoto doméstico in natura diretamente no córrego do Cachoeirinha, acúmulo de lixo em áreas inapropriadas e ruído provocado pelo intenso tráfego de veículos nos horários de pico. As figuras abaixo ilustram estes problemas identificados.

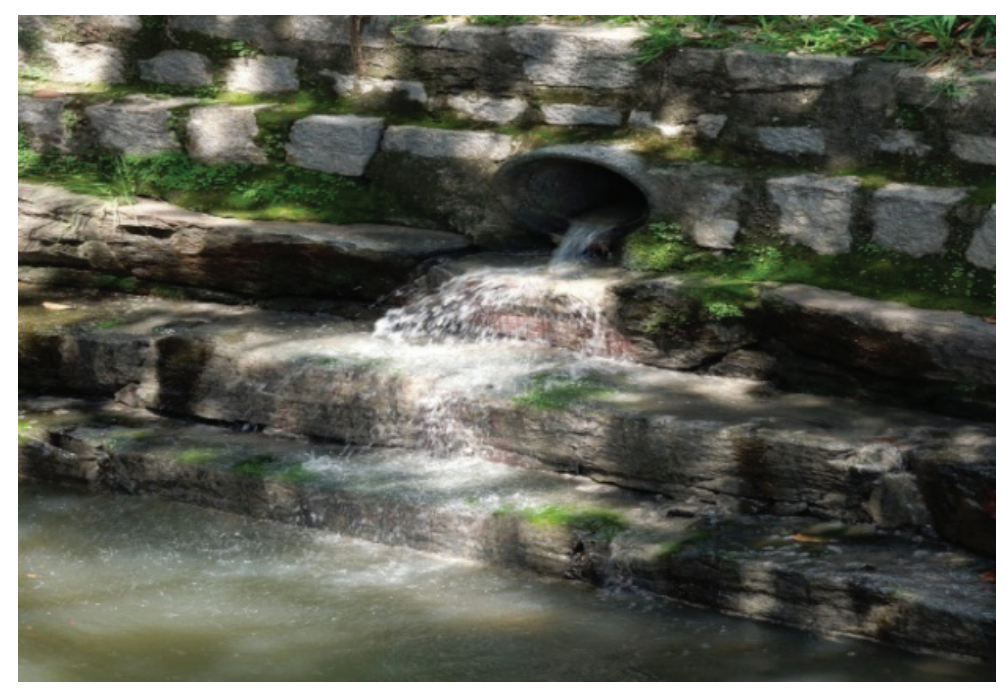

Figura 7 - Lançamento de esgoto doméstico no córrego Cachoeirinha. Fonte: Próprio Autor. 

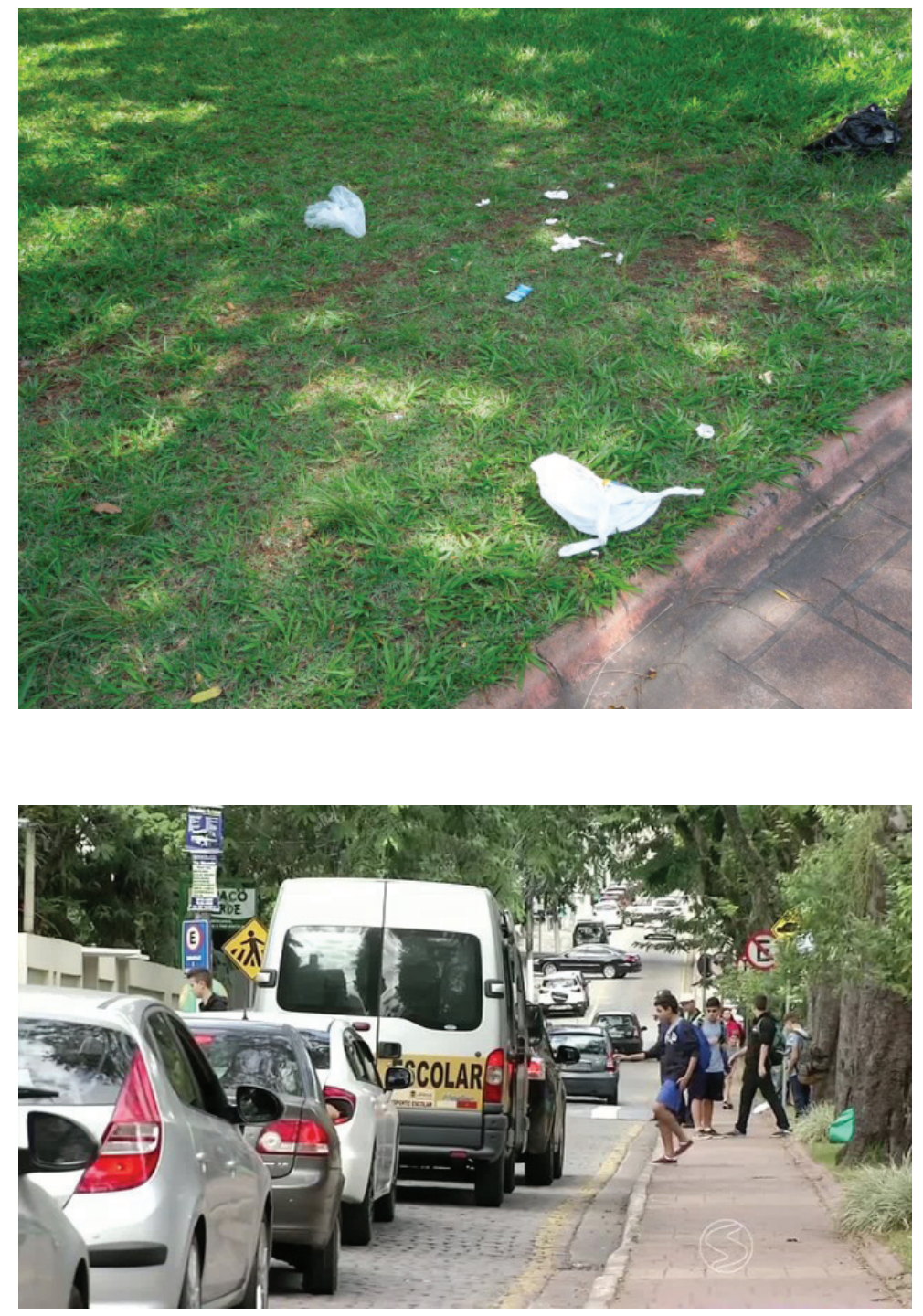

Figura 8 - Acúmulo de lixo na área do Jardim dos Inocentes. Fonte: Próprio Autor.
Figura 9 - Congestionamento no entorno do Jardim dos Inocentes. Fonte: O Globo, 2015.

Esses problemas comprometem a qualidade ambiental do Jardim dos Inocentes e consequentemente os serviços ecossistêmicos. Além disso, podem afetar a saúde pública e gerar impactos em outros locais.

O lançamento de esgoto doméstico no córrego Cachoeirinha compromete a qualidade da água, podendo aumentar a turbidez e a quantidade de matéria orgânica. Com a decomposição desta, pode-se gerar um mau cheiro desagradável, o que pode afastar as pessoas de frequentarem o local, além de afetar a biota aquática.

O lixo acumulado em áreas inapropriadas pode, com a ação das chuvas, ser carreado para o córrego Cachoeirinha, poluindo este e atingir o rio Paraíba do Sul. Além 
disto, devido à canalização do córrego, a ação das chuvas de verão pode ocasionar enchentes, as quais podem provocar danos à saúde pública e prejuízos econômicos ao município.

A população de Volta Redonda é de 262.970 mil habitantes (IBGE, 2015) e já são mais de 100 mil veículos emplacados (SMDET, 2015), tendo em média um veículo a cada 2,6 habitantes e a relação entre o número de carros e a área do município é de 549,76 carros $/ \mathrm{km}^{2}$. Estes valores são superiores até mesmo a outros municípios mais populosos, tais como Duque de Caxias, Nova Iguaçu, Petrópolis e Campos dos Goytacazes (IBGE, 2010 apud JUNIOR et al., 2013). Diante disto, pode-se afirmar que a questão do trânsito no município é emblemática, pois há congestionamentos em horários de pico, provocando ruídos e emissão de poluentes fósseis. Todos estes problemas também foram identificados na área do Jardim dos Inocentes.

\section{CONSIDERAÇÕES FINAIS}

A degradação dos ecossistemas naturais impulsionada pela urbanização desenfreada e pela falta de planejamento, em séculos passados, provocou sérios impactos ambientais à saúde pública e ao meio ambiente. Hoje, a discussão mundial está focada em como mitigar os problemas ambientais, sobretudo o aquecimento global. Assim sendo, além de suavizar a tonalidade cinzenta das cidades e de proporcionar melhor qualidade de vida urbana, as áreas/espaços verdes tornaram-se símbolos de defesa do meio ambiente pela sua degradação.

Nesse contexto, confere-se à arborização urbana como infraestrutura verde, de caráter multifuncional, uma ferramenta para a melhoria da qualidade de vida nos centros urbanos. Além disso, ela melhora o design paisagístico urbano alinhado com o paradigma da sustentabilidade.

Através do referencial teórico cruzado, com conceitos paisagísticos e de gestão ambiental, do apoio de ferramentas de SIG e levantamentos de campo foi possível obter um melhor entendimento das características ecológicas do Jardim dos Inocentes em Volta Redonda, assim como os atuais problemas ambientais enfrentados na área.

Percebe-se que a área verde do Jardim dos Inocentes exerce um papel importante para a qualidade de vida dos moradores do bairro Vila Santa Cecília, assim como para 
a fauna urbana, fornecendo diversos tipos de serviços ecossistêmicos. Vale ressaltar também sua importância na atenuação do aspecto cinzento das edificações, residências e dos pequenos estabelecimentos comerciais encontrados no entorno da área.

Os principais problemas ambientais identificados foram o ruído causado pelo intenso tráfego de veículos em horários de pico, o acúmulo de lixo em áreas inapropriadas e o despejo de esgoto doméstico diretamente no córrego Cachoeirinha. Portanto, recomendam-se algumas diretrizes para a mitigação destes problemas, tais como:

\section{Ruído}

- criar ciclovias em áreas mais movimentadas e criar interconexões com outros modais (ônibus);

- incentivar o uso do transporte público (ônibus);

- aumentar o número de linhas de ônibus municipais;

- diminuir ações facilitadoras ao fluxo de automóveis, como faixas de estacionamento;

- criar vias seletivas para ônibus, como faixas exclusivas à direita.

\section{Acúmulo de lixo}

- criar placas de sinalização que informem a proibição de descarte de lixo em locais inadequados, como "Jogue lixo no lixo";

- ampliar o número de contentores de lixo no entorno do Jardim dos Inocentes, sobretudo nas áreas pavimentadas utilizadas para a prática de atividades físicas e recreação;

- instalar contentores de coleta seletiva;

- fiscalizar e intensificar os serviços de limpeza pública no local.

\section{Despejo de esgoto doméstico no córrego Cachoeirinha}

- melhorar a rede de tratamento de esgoto doméstico;

- identificar áreas deficientes no tratamento de esgoto;

- instalar infraestruturas verdes nas margens do córrego, pois a vegetação auxiliaria na absorção da água das chuvas e de contaminantes e na retenção de sedimentos, além de melhorar a oxigenação da água; 
As propostas supracitadas visam melhorar a qualidade de vida dos moradores do bairro Vila Santa Cecília, principalmente daqueles que vivem no entorno do Jardim dos Inocentes. Além disso, tendem a melhorar e a diversificar os serviços ecossistêmicos.

É necessário também que nas políticas públicas e em futuros projetos de obras civis do Município de Volta Redonda passe a incorporar conceitos e técnicas preconizadas no planejamento urbano sustentável, sempre contemplando os ecossistemas naturais nos projetos e adotando, sempre que possível, infraestruturas verdes que são multifuncionais.

\section{REFERÊNCIAS}

ANDRADE, D. C. Modelagem e valoração de serviços ecossistêmicos: uma contribuição da Economia Ecológica. Tese (Doutorado) - Instituto de Economia da Universidade Estadual de Campinas (UNICAMP). Campinas, 2010.

COSTANZA, R., D'ARGE, R., DE GROOT, R.S., FARBER, S., GRASSO, M., HANNON, B., LIMBURG, K., NAEEM, S., O'NEILL, R.V., PARUELO, J., RASKIN, R.G., SUTTON, P., VAN DEN BELT, M., 1997. The value of the world's ecosystem services and natural capital. Nature 387, 253-260.

DAILY, G., 1997. Nature's services: societal dependence on natural ecosystem. Washington D.C.: Island Press.

DE GROOT, R.S., WILSON, M.A., BOUMANS, R.M.J., 2002. A typology for the classification, description, and valuation of ecosystem functions, goods and services. Ecological Economics 41, 393-408.

DIAS, J. E. \& GARCIA, J. M. P. Aplicação do mapa de unidades geomorfológicas para fins de planejamento de uso e ocupação de territórios por meio da ferramenta de geoprocessamento: estudo de caso no município de Volta Redonda, RJ. Revista Eletrônica Geoaraguaia. Barra do Garças - MT. V. 4, n.2, p 97 - 112. Julho/Dezembro. 2014.

FEEMA - Fundação Estadual de Engenharia do Meio Ambiente. 1990. Perfil Ambiental Município de Volta Redonda. Volta Redonda, 98p. 
FONTES, A. M. M. \& LAMARÃO, S. T. N. Volta Redonda: história de uma cidade ou de uma usina? In: Revista Rio de Janeiro, n. 18-19, jan.-dez. 2006

HECKMAIER, T. P. C.; Indústria e Desenvolvimento Regional no Médio Vale do Paraíba, RJ: A Companhia Siderúrgica Nacional como fator de atração de novos fixos no Interior Fluminense. In: XVII Encontro Nacional de Geógrafos, 2012, Belo Horizonte. Anais do XVII Encontro Nacional de Geógrafos, 2012. p. 1-10.

IBGE-Instituto Brasileiro de Geografiae Estatística. Volta Redonda. Disponívelem: http:// cidades.ibge.gov.br/painel/fotos.php?lang=_PT\&codmun=330630\&search=\%7Cvoltaredonda. Acesso em: 28/11/2015.

IPPUVR - Instituto de Pesquisa e Planejamento Urbano de Volta Redonda. 1994. Informações para o Plano Diretor: Coleção cadernos de Planejamento. v.1.Volta Redonda, Edição Própria.

JUNIOR, I. C. L.; RIBEIRO, L. C.; SILVA, S. S. Avaliação do desempenho das seguradoras de automóveis na visão do cliente por meio de um modelo de decisão multicritério. In: Revista UNIABEU Belford Roxo, v.6, n.14, set.- dez. 2013.

LIMONAD, E. Os lugares da urbanização: o caso do interior fluminense. Tese de doutorado, FAU/USP, São Paulo, 1996.

LLARDENT, L. R. A. Zonas verdes y espaços livres en la ciudad. Madrid: Closas. Orcoyen, 1982.

MILLENNIUM ECOSYSTEM ASSESSMENT (MA), 2003. Ecosystem and Human Well-Being: a framework for assessment. Island Press, Washington, DC.

MILLENNIUM ECOSYSTEM ASSESSMENT (MEA), 2005. Ecosystem and Human WellBeing: Synthesis. Washington D.C.: Island Press.

MILLENNIUM ECOSYSTEM ASSESSMENT (MA), 2003. Ecosystem and Human Well-Being: a framework for assessment. Island Press, Washington, DC.

O Globo. Bom Dia Rio flagra irregularidades no trânsito em Volta Redonda, RJ. Disponível em: http://g1.globo.com/rij/sul-do-rio-costa-verde/noticia/2015/06/rjtv-flagra- 
irregularidades-no-transito-perto-de-colegios-de-volta-redonda.html. Acesso em: 27/12/2015.

PAIVA, R. F. P. S. Morbidade hospitalar por doenças associadas à poluição do ar na cidade de Volta Redonda, Rio de Janeiro: casos e custo econômico. In: Cad. saúde colet. vol.22 no.2 Rio de Janeiro Apr./June 2014.

RODRIGUES, E. F. Diagnóstico de Cheias Urbanas na Cidade de Volta Redonda RJ. Dissertação (Mestrado) - UFRJ/ COPPE/ Programa de Engenharia Civil, 2008.

SMDET - Secretaria Municipal de Desenvolvimento Econômico e Turismo. Disponível em: http://www.smdet.com.br/ver.php?cod=44. Acesso em 03/12/2015.

SOR, J. L.; CLEVELÁRIO JÚNIOR, J.; GUIMARÃES, L. T.; MORENO, R. A. M. Relatório piloto com aplicação da metodologia IPPS ao estado do Rio de Janeiro: uma estimativa do potencial de poluição industrial do ar. Rio de Janeiro: Instituto Brasileiro de Geografia e Estatística; 2008. 